\title{
HIỆU QUẢ GIẢM ĐAU GÂY TÊ LIÊN TỤC KHOANG CẠNH SỐNG NGỰC BẰNG HỖN HỢP BUPIVACAIN-FENTANYL Ở BỆNH NHẦN CHẤN THƯƠNG NGỰC KÍN CÓ GÃY NHIỀU SƯờn
}

Đặng Tuấn Nghĩa*, Nguyễn Ngọc Trung*, Nguyễn Văn Nam*, Trần Thanh Bình*, Vũ Anh Hải*, Lại Hợp Hậu*,
Nguyền Khánh*, Phan Duy Nguyên*, Nguyê̂n Trung Kiên*, Nguyến Truờng Giang*

\section{TÓM TẮT}

Nghiên cứu mô tả cắt ngang 172 bệnh nhân chấn thương ngực kín gãy nhiều sườn một bên. Đặt catheter khoang cạnh sống ngực, bơm liều khởi đầu qua catheter dung dịch bupivacain $0,25 \%+$ fentanyl $2 \mu \mathrm{g} / \mathrm{ml}$ liều $0,3 \mathrm{ml} / \mathrm{kg}$ sau đó truyền $0,1 \mathrm{ml} / \mathrm{kg} / \mathrm{h}$ dung dịch bupivacaine $0,125 \%$ + fentanyl $2 \mu \mathrm{g} / \mathrm{ml}$. Phân loại nguyên nhân chấn thương, tai nạn giao thông chiếm chủ yếu gây chấn thương ngực kín $(69,1 \%)$; số lượng xương sườn gãy từ $3-5$ và từ $6-8$ lần lượt là $76,1 \%$ và $23,9 \%$. Tỉ lệ tràn máu, tràn khí là $64,5 \%$ và $7,6 \%$; tràn máu kết hợp tràn khí là $27,9 \%$. Điểm đau VAS giảm khi nghỉ và khi ho $(\mathrm{p}<0,05)$; FVC, FEV1 tăng sau gây tê khoang cạnh sống 30 phút $(\mathrm{p}<0,05)$. Có $6,4 \%(\mathrm{n}=11)$ bệnh nhân cần truyền bổ sung paracetamol giải cứu đau. Không có bệnh nhân nào ức chế hô hấp, suy hô hấp hoặc có dấu hiệu ngộ độc thuốc tê. Gây tê liên tục khoang cạnh sống ngực bằng bupivacain $0,125 \%$-fentanyl $2 \mu \mathrm{g} / \mathrm{ml}$ có hiệu quả giảm đau cao và an toàn trong điều trị cho bệnh nhân chấn thương ngực kín có gãy nhiều xương sườn.

*Tù khóa: chấn thuoong ngực kín, gây tê cạnh sống ngục, gãy nhiều xuơng suờn.

\section{SUMMARY}

THORACIC PARAVERTEBRAL ANALGESIA

FOR TREATMENT BLUNT CHEST TRAUMA WITH MULTIPLE RIB FRACTURES

The study was carried out on 172 blunt chest trauma patients in prospective nonrandomized case series. An initial bolus dose of $0.3 \mathrm{ml} / \mathrm{kg}$ of bupivacaine $0.25 \%$ plus fentanyl $2 \mu \mathrm{g} / \mathrm{ml}$ was used following by continuous infusion with $0.1 \mathrm{ml} / \mathrm{kg} / \mathrm{h}$ of bupivacaine $0.125 \%$ plus fentanyl $2 \mu \mathrm{g} / \mathrm{ml}$. Pain severity was assessed by visual analogue scale (VAS) at rest and during coughing; bedside spirometry was measured 5 times in 3 consecutive days after paravertebral block. Traffic accidents (69.1\%) was major reason for blunt chest trauma; the number of ribs fracture ranged from $3-5(76.1 \%)$ and $6-8$ (23.9\%). The rate of hemothorax, pneumothorax and the combination hemothorax-pneumothorax were $64.5 \%, 7.6 \%$ and $27.9 \%$ respectively. There was significant improvement in pain score at rest and during coughing, respiratory rate, FVC and FEV1 $(p<0.05) 30$ min after initial bolus dose, which were sustained during continuous thoracic paravertebral infusion $72 \mathrm{~h}(\mathrm{p}<0.05)$. The rate of analgesic rescue by paracetamol infusion was $6.4 \%$. No patient had respiratory depression or respiratory failure or signs of local anesthetic toxicity. The result shows that thoracic paravertebral analgesia with bupivacaine and fentanyl provided a good efficacy for pain management in patients with unilateral MRF.

*Keywords: chest trauma, thoracic paravertebral analgesia, multiple rib fracture.

\section{I. ĐẶT VẤN ĐỀ}

Gãy nhiều xương sườn là nguyên nhân

* Bệnh viện Quân y 103-Học viện Quân y Ngưòi chịu trách nhiệm khoa học: PGS.TS. Nguyễn Truòng Giang Ngày nhận bài: 01/05/2018 - Ngày Cho Phép Đăng: 20/05/2018

Phản Biện Khoa học: GS.TS. Bùi Đức Phú PGS.TS. Đặng Ngọc Hùng 
chính gây đau một cách trầm trọng và ảnh hưởng bất lợi đến chức năng hô hấp của bệnh nhân. Giảm đau đầy đủ được coi là trị liệu chủ yếu cho các bệnh nhân gãy nhiều sườn, giúp bệnh nhân dễ tiến hành lý liệu pháp hô hấp để đẩy nhanh quá trình hồi phục [9], [10].

Có nhiều phương pháp giảm đau nhưng gây tê khoang cạnh sống ngực chỉ ức chế cảm giác một số phân đoạn da, lại ít gây tai biến là một lựa chọn tốt để kiểm soát đau cũng như cải thiện chức năng thông khí ở các bệnh nhân chấn thương ngực có gãy nhiều xương sườn [1], [7]. Eason và Wyatt [3] đã mô tả trường hợp đầu tiên giảm đau sau chấn thương ngực qua đường khoang cạnh sống ngực có gãy nhiều sườn năm 1979. Mặc dù tiêm một liều thuốc tê vào khoang cạnh sống ngực có hiệu quả giảm đau cao cho bệnh nhân gãy sườn một bên ngực nhưng có nhược điểm là không tạo ra tác dụng giảm đau kéo dài để hỗ trợ bệnh nhân tập vật lý trị liệu trong các ngày tiếp theo. Một số nghiên cứu đã thông báo gây tê liên tục khoang cạnh sống ngực bằng thuốc tê qua catheter có hiệu quả giảm đau kéo dài ở các bệnh nhân gãy nhiều xương sườn [7], [11]. Tuy nhiên, hiệu quả giảm đau của gây tê liên tục khoang cạnh sống ngực ở bệnh nhân gãy nhiều xương sườn vẫn chưa được nghiên cứu và báo cáo một cách có hệ thống ở Việt Nam. Vì vậy, đề tài được thực hiện nhằm đánh giá hiệu quả giảm đau của gây tê liên tục khoang cạnh sống ngực bằng bupivacain và fentanyl ở bệnh nhân gãy nhiều xương sườn.

\section{II. ĐỐI TƯợNG VÀ PHƯƠNG PHÁP NGHIÊN CÚU}

\section{1. Đối tượng nghiên cứu}

Gồm 172 bệnh nhân chấn thương ngực kín có gãy từ 3 xương sườn trở lên được điều trị tại khoa phẫu thuật lồng ngực, Bệnh viện Quân y 103 từ tháng 12/2013 đến tháng 12/2016.

\subsection{Phương pháp nghiên cứu}

Gây tê khoang cạnh sống ngực được thực hiện dưới điều kiện vô khuẩn, bệnh nhân trong tư thế ngồi, kỹ thuật được thực hiện theo quy trình của Eason và Wyat [3]. Mức chọc kim gây tê chọn ở dưới mức gãy xương sườn 2 phân đốt hoặc ở giữa các mức phân đốt da cần chi phối, cách đường giữa 2-2,5 cm.

Gây tê tại vị trí chọc kim. Tiến kim vuông góc với mặt da cho tới khi gặp mỏm ngang của thân đốt sống ngực, thường ở độ sâu từ $2-4 \mathrm{~cm}$. Sau đó lui kim khoảng $1 \mathrm{~cm}$ và tiến trượt qua bờ trên của mỏm ngang, sử dụng kỹ thuật mất sức cản với không khí. Sau khi xác định được khoang cạnh sống, rút nòng kim, luồn catheter vào khoang cạnh sống $2-3 \mathrm{~cm}$. Rút kim, cố định catheter bằng opsite dọc theo cột sống ngực. Hút thử qua catheter để khẳng định không có máu hoặc dịch não tủy chảy ra.

Chuyển bệnh nhân sang tư thế nằm ngửa. Tiêm chậm trên 3 phút liều khởi đầu 0,3 $\mathrm{ml} / \mathrm{kg}$ dung dịch bupivacain $0,25 \%$ có $2 \mu \mathrm{g}$ fentanyl $/ \mathrm{ml}$ qua catheter. Tiếp theo truyền qua bơm tiêm điện dung dịch bupivacain 0,125\% có $2 \mu \mathrm{g} / \mathrm{ml}$ với tốc độ $0,1 \mathrm{ml} / \mathrm{kg} / \mathrm{h}$. Trong thời gian theo dõi giảm đau, tốc độ truyền vào khoang cạnh sống có thể tăng 1-2 ml/h cho tới liều truyền tối đa $0,2 \mathrm{ml} / \mathrm{kg} / \mathrm{h}$ tùy thuộc vào mức độ đau của bệnh nhân; hoặc bolus 3-4 ml dung dịch thuốc bupivacain $0,125 \%+2 \mathrm{mcg}$ fentanyl $/ \mathrm{ml}$ nếu điểm VAS khi ho lớn hơn 4 hoặc khi bệnh nhân yêu cầu giảm đau thêm.

Thông số của bệnh nhân được ghi nhận tại thời điểm trước gây tê (H0), sau gây tê 30 phút (H1), 24 giờ $(\mathrm{H} 2), 48$ giờ $(\mathrm{H} 3)$ và 72 giờ $(\mathrm{H} 4)$. Số liệu được xử lý bằng phần mềm thống kê SPSS 22.0 


\section{KẾT QUẢ VÀ BÀN LUẬN}

Bảng 3.1: Đặc điểm chung

\begin{tabular}{|l|l|c|}
\hline Đặc điểm tổn thương & \multicolumn{2}{|c|}{ n (\%) } \\
\hline Tuồi & Nam & $139(80,8)$ \\
\cline { 2 - 3 } Giới & Nũ̃ & $33(19,2)$ \\
\hline \multirow{3}{*}{ Nguyên nhân } & Tai nạn giao thông & $119(69,1)$ \\
\cline { 2 - 3 } & Ngã cao & $42(24,4)$ \\
\cline { 2 - 3 } & Khác & $11(6,5)$ \\
\hline \multirow{2}{*}{ Số xương sườn gãy } & $3-5$ & $131(76,1)$ \\
\cline { 2 - 3 } & $6-8$ & $41(23,9)$ \\
\hline \multirow{3}{*}{ Khoang màng phổi } & Tràn máu & $111(64,5)$ \\
\cline { 2 - 3 } & Tràn khí & $13(7,6)$ \\
\cline { 2 - 3 } & Tràn máu + tràn khí & $11(27,9)$ \\
\hline Số bệnh nhân cần giảm đau bổ xung & & 172 \\
\hline
\end{tabular}

Độ tuổi trong nghiên cứu trong phạm vi từ 23 đến 87 tuổi. Tuổi trung bình của các bệnh nhân là 53,6 tuổi và chủ yếu nằm trong khoảng từ 40-60 tuổi. Tỷ lệ nam/nữ là 137/35. Nhìn chung, các bệnh nhân đều nằm trong lứa tuổi lao động. Tỷ lệ gãy từ 3 đến 5 xương sườn là $76,1 \%$. Tỷ lệ tràn máu khoang màng phổi là $64,5 \%$, tràn khí tràn máu khoang màng phổi là $27,9 \%$. Theo những nghiên cứu mới đây, mức độ đau tỷ lệ thuận với số lượng xương sườn gãy của bệnh nhân và giảm đau được coi là phương pháp điều trị chủ yếu cho bệnh nhân gãy nhiều xương sườn [8], [9], [12].

Bảng 3.2: Vị trí chọc kim Tuohy

\begin{tabular}{|c|c|c|}
\hline Vị trí chọc kim & $\mathbf{n}$ & Tỷ lệ \% \\
\hline T3-T4 & 9 & 5.2 \\
\hline T4-T5 & 21 & 12.2 \\
\hline T5-T6 & $\mathbf{8 1}$ & $\mathbf{4 7 . 1}$ \\
\hline T6-T7 & $\mathbf{4 6}$ & $\mathbf{2 6 . 8}$ \\
\hline T7-T8 & 9 & 5.2 \\
\hline T8-T9 & 6 & 3.5 \\
\hline Tống & 172 & 100 \\
\hline
\end{tabular}

Khoang cạnh sống ngực là một khoang hình chữ $\mathrm{V}$ nằm hai bên bên cột sống chưa thần kinh tủy sống, rễ lưng, các nhánh thông và chuỗi thần kinh giao cảm. Tiêm thuốc tê vào khoang cạnh sống tạo nên ức chế cảm giác thân thể và giao cảm một bên, điều đó tạo thuận lợi cho giảm đau một bên cho các bệnh nhân chấn thương ngực [4], [12]. Gây tê khoang cạnh sống ngực thuốc sẽ lan tỏa lên trên và xuống dưới vị trí chọc kim làm ức chế dẫn truyền cảm giác ở các mức kế tiếp và lan tỏa cả vào khoang ngoài màng cứng. Sự lan tỏa ức chế cảm giác và thần kinh giao cảm cùng bên của nhiều rễ sau giúp ức chế dẫn truyền cảm giác đau nhiều phân đốt da liền kề ở ngực [5]. Trong 172 bệnh nhân nghiên cứu, catheter được đặt thành công ở khoảng giữa khoanh đoạn tủy thứ 3 đến khoanh đoạn tủy thứ 8 , chủ yếu ở mức T5-T6 chiếm 47,1\%. 
Bảng 3.3: Hiệu quả của gây tê liên tục khoang cạnh sống ngực

\begin{tabular}{|l|c|c|c|c|c|c|}
\hline \multirow{2}{*}{ Chỉ tiêu } & \multicolumn{7}{|c|}{ Thời điểm (n-172) } & \multirow{2}{*}{ p } \\
\cline { 2 - 6 } Mạch (ck/phút) & H0 & H1 & H2 & H3 & H4 & \\
\hline Huyết áp (mmHg) & $137,1 \pm 9,2$ & $133,6 \pm 8,1^{*}$ & $125,6 \pm 9,0^{*}$ & $120,6 \pm 7,4^{*}$ & $112,6 \pm 7,6^{*}$ & $>0,05$ \\
\hline $\mathrm{SpO}_{2}$ (\%) & $91,7 \pm 2,4$ & $94,4 \pm 1,4^{*}$ & $95,7 \pm 1,2^{*}$ & $98,9 \pm 2,4^{*}$ & $99,7 \pm 1,3^{*}$ & $<0,05$ \\
\hline FVC (lít) & $\begin{array}{c}1,1 \pm 0,1 \\
(0,7-1,6)\end{array}$ & $\begin{array}{c}1,4 \pm 0,1^{*} \\
(0,8-1,7)\end{array}$ & $\begin{array}{c}1,9 \pm 0,6^{*} \\
(1,1-0,3)\end{array}$ & $\begin{array}{c}2,1 \pm 0,9^{*} \\
(1,2-2,4)\end{array}$ & $\begin{array}{c}2,3 \pm 1,0^{*} \\
(1,1-2,6)\end{array}$ & $<0,05$ \\
\hline FEV1 (lít) & $\begin{array}{c}1,3 \pm 0,4 \\
(0,8-1,5)\end{array}$ & $\begin{array}{c}1,5 \pm 0,7^{*} \\
(0,8-2,0)\end{array}$ & $\begin{array}{c}2,1 \pm 0,6^{*} \\
(1,4-2,4)\end{array}$ & $\begin{array}{c}2,2 \pm 1,1^{*} \\
(1,4-2,6)\end{array}$ & $\begin{array}{c}2,5 \pm 1,1^{*} \\
(1,5-2,6)\end{array}$ & $<0,05$ \\
\hline VAS khi nghỉ & $7,1 \pm 1,1$ & $4,6 \pm 0,5^{*}$ & $3,3 \pm 0,4^{*}$ & $1,4 \pm 0,5^{*}$ & $0,4 \pm 0,3^{*}$ & $<0,05$ \\
\hline VAS lúc ho & $7,8 \pm 0,5$ & $5,7 \pm 0,9^{*}$ & $4,7 \pm 0,4^{*}$ & $2,8 \pm 0,5^{*}$ & $0,7 \pm 0,3^{*}$ & $<0,05$ \\
\hline
\end{tabular}

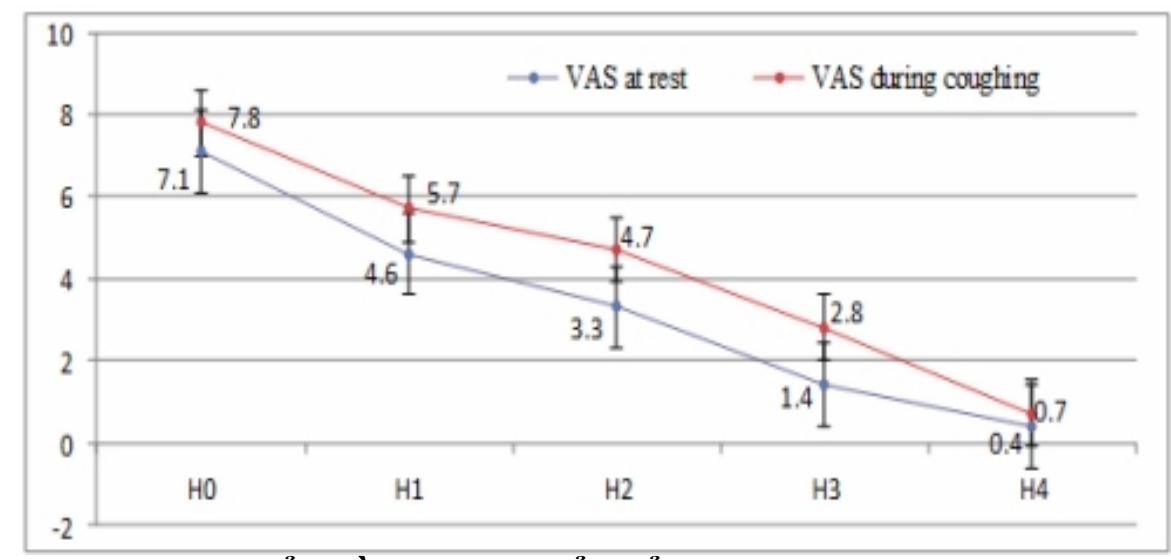

Biểu đồ 31: Thay đổi điểm VAS sau gây tê

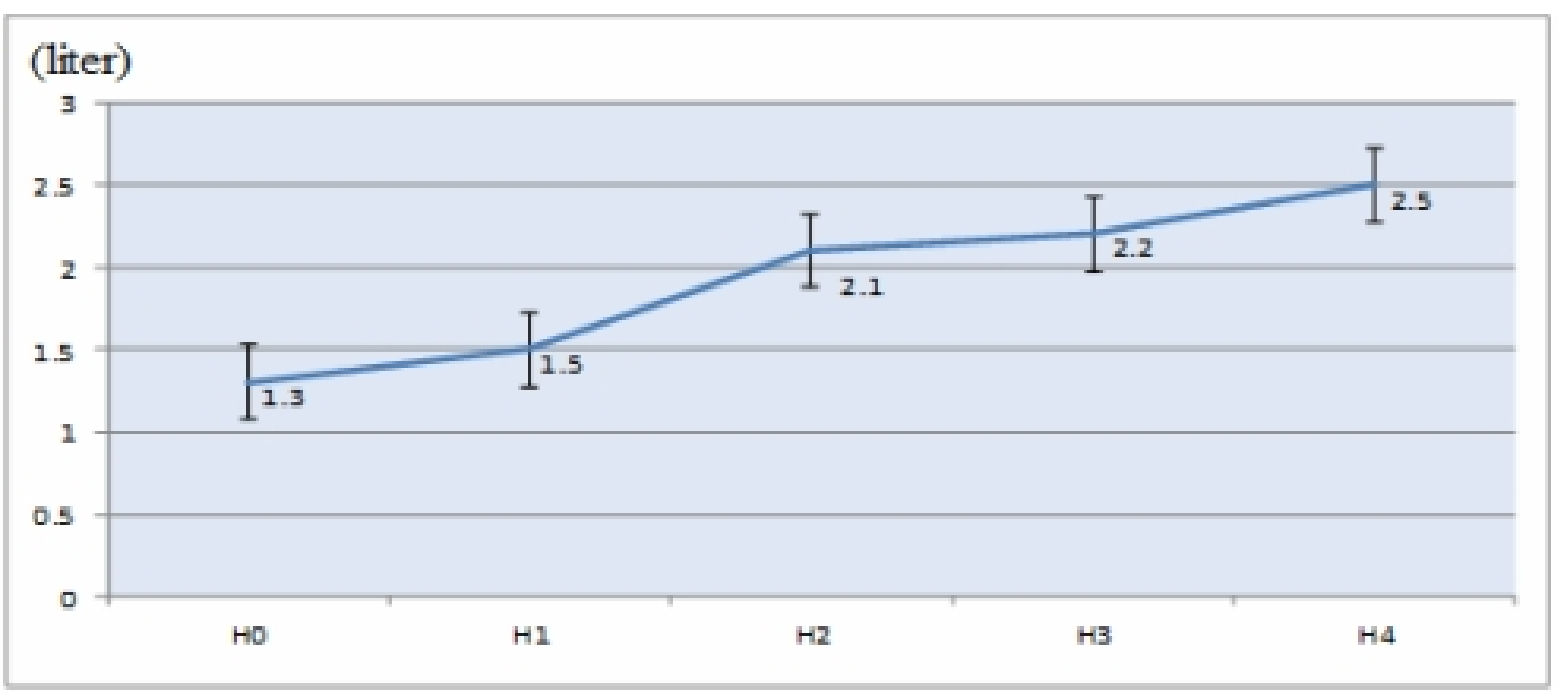

Biểu đồ 3.2: Thay đổi FEV1 sau gây tê 
Kết quả nghiên cứu cho thấy điểm VAS khi nghỉ và lúc ho của các bệnh nhân giảm có ý nghĩa thống kê trong ba ngày theo dõi giảm đau. Khi nghỉ, điểm VAS trung bình giảm từ $7,1 \pm 1,1$

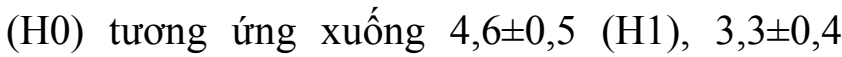
$(\mathrm{H} 2), 1,4 \pm 0,5(\mathrm{H} 3), 0,4 \pm 0,3(\mathrm{H} 4)$ với $\mathrm{p}<0,05$. Điểm VAS khi ho của bệnh nhân cũng có diễn biến giảm đau tương tự với $\mathrm{p}<0,05$. Không bệnh nhân nào phải tiêm thêm thuốc giảm đau họ morphin đường tĩnh mạch như là cách giải cứu đau sau khi đã truyền liên tục thuốc tê trên vào khoang cạnh sống. Kết quả này phù hợp với kết quả nghiên cứu của một số tác giả như Davies RG [2] và Kamarka [9]. Tuy nhiên, theo Fibla J.J [3], điểm VAS thường đạt giá trị thấp nhất sau khi tiêm liều khởi đầu kết hợp với truyền liên tục. Khi bệnh nhân đau nặng được thực hiện giảm đau đường cạnh sống ngực, hiệu quả giảm đau sẽ được bệnh nhân cảm nhận ngay sau liều đầu tiên, điểm VAS giảm nhanh đáng kể. Gây tê liên tục khoang cạnh sống ngực có hiệu quả giảm đau sau mổ cao so với giảm đau đường tĩnh mạch bằng morphin và tỷ lệ tác dụng không mong muốn thấp hơn.

Theo nghiên cứu của Kamark thực hiện trên 15 bệnh nhân có tổn thương gãy xương sườn một bên, điểm VAS giảm có ý nghĩa thống kê cả khi nghỉ và vận động trong 4 ngày liên tiếp ( $\mathrm{p}<$ 0,01 ) [9]. Với chất lượng giảm đau tốt cả khi nghỉ và khi ho, các chỉ số chức năng thông khí được cải thiện đáng kể, giảm tần số hô hấp (bảng 4) với $\mathrm{p}<0,05$. Các chỉ số $\mathrm{SpO}_{2}, \mathrm{FVC}, \mathrm{FEV} 1$ tăng cao hơn có ý nghĩa thống kê so với thời điểm $\mathrm{H} 0, \mathrm{p}$ $<0,05$; các bệnh nhân có thể hít thở sâu và ho khạc rễ dàng. Hiệu quả tốt này được kéo dài trong suốt 3 ngày gây tê liên tục khoang cạnh sống ngực do thuốc được truyền liên tục vào khoang cạnh sống. Kỹ thuật gây tê khoang cạnh sống là một kỹ thuật đơn giản và dễ thực hiện so với kỹ thuật gây tê ngoài màng cứng và có hiệu quả giảm đau cao ở các bệnh nhân gãy nhiều xương sườn. Nghiên cứu của Richardson trên 100 bệnh nhân người lớn trưởng thành được giảm đau cạnh sống sau phẫu thuật ngực thấy rằng chức năng phổi được đánh giá bằng PEFR cũng được cải thiện đáng kể $(\mathrm{p}<0,05)$ khi so sánh với gây tê ngoài màng cứng ngực [11].

Không gặp biến chứng nào trong số các bệnh nhân nghiên cứu. Tuy nhiên, cần theo dõi sát khi thực hiện kỹ thuật để giảm thiểu tác dụng không mong muốn hoặc biến chứng khi làm với số lượng nhiều bệnh nhân. Với hiệu quả giảm đau cao của gây tê liên tục khoang cạnh sống có tác dụng cải thiện chức năng hô hấp và tim mạch ở những bệnh nhân chấn thương ngực kín có gãy nhiều xương sườn, giúp bệnh nhân bình phục nhanh hơn.

\section{KẾT LUẬN}

Gây tê liên tục khoang cạnh sống ngực cho 172 bệnh nhân chấn thương ngực kín gãy nhiều xương sườn có hiệu quả giảm đau cao cả khi nghỉ và ho. Giá trị $\mathrm{FVC}$ và $\mathrm{FEV1} \mathrm{tăng} \mathrm{có} \mathrm{ý}$ nghĩa thống kê so với trước khi điều trị.

\section{TÀI LIỆU THAM KHẢO}

1. Cheema, S. P., D. Ilsley, J. Richardson, and S. Sabanathan, (1995), "A thermographic study of paravertebral analgesia". Anaesthesia. 50(2), 118-21

2. Davies, R. G., P. S. Myles, and J. M. Graham, (2006), "A comparison of the analgesic efficacy and side-effects of paravertebral vs epidural blockade for thoracotomy--a systematic review and metaanalysis of randomized trials". $\mathrm{Br} J$ Anaesth. 96(4), 418-26

3. Fibla, J. J., L. Molins, J. M. Mier, A. Sierra, D. Carranza, and G. Vidal, (2011), "The efficacy of paravertebral block using a catheter technique for postoperative analgesia in thoracoscopic surgery: a randomized trial". Eur J Cardiothorac Surg. 40(4), 907-11 
4. Gabram, S. G., R. J. Schwartz, L. M. Jacobs, D. Lawrence, M. A. Murphy, J. S. Morrow, J. S. Hopkins, and R. F. Knauft, (1995), "Clinical management of blunt trauma patients with unilateral rib fractures: a randomized trial". World J Surg. 19(3), 388-93

5. Galvagno, S. M., Jr., C. E. Smith, A. J. Varon, E. A. Hasenboehler, S. Sultan, G. Shaefer, K. B. To, A. D. Fox, D. E. Alley, M. Ditillo, B. A. Joseph, B. R. Robinson, and E. R. Haut, (2016), "Pain management for blunt thoracic trauma: A joint practice management guideline from the Eastern Association for the Surgery of Trauma and Trauma Anesthesiology Society". J Trauma Acute Care Surg. 81(5), 936-951

6. Hashemzadeh, S., K. Hashemzadeh, H. Hosseinzadeh, R. Aligholipour Maleki, and S. E. Golzari, (2011), "Comparison thoracic epidural and intercostal block to improve ventilation parameters and reduce pain in patients with multiple rib fractures". $J$ Cardiovasc Thorac Res. 3(3), 87-91

7. Karmakar, M. K. and A. M. Ho, (2003), "Acute pain management of patients with multiple fractured ribs". J Trauma. 54(3), 615-25
8. Karmakar, M. K., P. T. Chui, G. M. Joynt, and A. M. Ho, (2001), "Thoracic paravertebral block for management of pain associated with multiple fractured ribs in patients with concomitant lumbar spinal trauma". Reg Anesth Pain Med. 26(2), 169-73

9. Karmakar, M. K., L. A. Critchley, A. M. Ho, T. Gin, T. W. Lee, and A. P. Yim, (2003), "Continuous thoracic paravertebral infusion of bupivacaine for pain management in patients with multiple fractured ribs". Chest. 123(2), 424-31

10. Mostafa Kamel and Amr Abdelfatah, (2010), "Pain mamagement in blunt chest trauma". Ain Shams Journal of Anesthesiology. 3(1), 89-96

11. Richardson, J., P. A. Lonnqvist, and Z. Naja, (2011), "Bilateral thoracic paravertebral block: potential and practice". $\mathrm{Br} J$ Anaesth. 106(2), 164-71

12. Simon, B. J., J. Cushman, R. Barraco, V. Lane, F. A. Luchette, M. Miglietta, D. J. Roccaforte, R. Spector, and East Practice Management Guidelines Work Group, (2005), "Pain management guidelines for blunt thoracic trauma". J Trauma. 59(5), 1256-67. 